\title{
ESTUDO ETNOGRÁFICO: POTENCIAL PSICOTERÁPICO DO USO RITUAL DA AYAHUASCA EM CONTEXTOS NEOXAMÂNICOS
}

\author{
Odair Almeida ${ }^{1}$
}

\begin{abstract}
Resumo
Utilizando algumas das principais práticas constitutivas do método etnográfico empreendi uma investigação a respeito do potencial psicoterápico do uso da Ayahuasca, especificamente no contexto de rituais neoxamânicos. Neste relato apresento as principais etapas da pesquisa, destacando algumas considerações a respeito de duas visitas a campo, nas quais realizei o trabalho de observação participante, e três entrevistas com sujeitos do campo. Além disso, descrevo brevemente uma situação marcante vivenciada em campo e relaciono minhas impressões e reflexões com conteúdos do referencial bibliográfico. Ao final desenvolvo uma proposta de interpretação, segundo a qual a hipótese inicial, relacionada ao caráter terapêutico dos rituais com ayahuasca e seus desdobramentos, foi satisfatoriamente corroborada por minhas experiências e observações em campo e pela relação com os sujeitos.
\end{abstract}

Palavras-chave: Neoxamanismo, Ayahuasca, Ritual.

\begin{abstract}
Using some of the main constitutive practices of the ethnographic method, I undertook an investigation regarding the psychotherapeutic potential of the use of Ayahuasca, specifically in the context of neoxamanic rituals. In this report I present the main stages of the research, highlighting some considerations regarding two field visits, in which I performed participant observation work, and three interviews with field subjects. In addition, I briefly describe a striking situation experienced in the field and relate my impressions and reflections to the contents of the bibliographic reference. At the end I develop a proposal of interpretation, according to which the initial hypothesis, related to the therapeutic character of rituals with ayahuasca and its unfolding, was satisfactorily corroborated by my experiences and observations in the field and by the relation with the subjects.
\end{abstract}

Keywords: Neoxamanism, Ayahuasca, Ritual.

\footnotetext{
1 Universidade Federal do ABC. E-mail: odasilva@outlook.com.br 


\section{Problema/pergunta e hipótese}

Em meio à imensa curiosidade e às inúmeras questões instigantes relacionadas ao fenômeno da utilização ritual da ayahuasca no interior ou nas proximidades dos grandes centros urbanos, optei por investigar o tema das finalidades e significações atribuídas pelos adeptos de tais práticas às suas próprias experiências com a bebida enteógena, focando mais especificamente na possibilidade da existência de um caráter terapêutico.

A hipótese com a qual trabalhei é a de que os rituais envolvendo a ingestão de ayahuasca, dentro do contexto das práticas neoxamânicas, não se constituem apenas como atividades religiosas ou esotéricas associadas pelos participantes a crenças ou doutrinas espiritualistas específicas, apesar das diversas referências e aspectos hieráticos, mas possuem um acentuado potencial terapêutico, caracterizado pela contribuição ao entendimento ou resolução de questões psíquicas, emocionais e relacionais, através do esforço de introspecção realizado durante os trabalhos e em seus desdobramentos.

Vinícius Paiva desenvolveu, entre outros tópicos, a hipótese a respeito do caráter terapêutico da ayahuasca em seu estudo etnográfico publicado em 2015. O autor apresenta uma variedade de relatos de sujeitos do campo em questão atestando os benefícios psicoterápicos relacionados ao uso da bebida em contextos ritualísticos.

Os rituais xamânicos e, de forma mais geral, a experiência enteógena com a ayahuasca, estimulam processos de reorganização mental e conscientização, promovendo mudanças comportamentais e, mais profundamente, processos de cura (PAIVA, 2015, p. 94).

\section{Escolha do campo e sua descrição}

A escolha do campo se deu através da articulação de ao menos três fatores: (1) interesse pessoal pelo assunto, fortalecido por uma vivência recente relacionada ao mesmo; (2) contato constante e direto com pessoas envolvidas intimamente com o campo; (3) conhecimento e contato - menos constante e/ou indireto - com outras pessoas envolvidas de alguma forma com o campo.

Tratando mais detalhadamente de cada um desses três elementos motivacionais e estabelecendo uma relação entre eles, posso dizer que tenho curiosidade a respeito do assunto há pelo menos dez anos e já tive disposição para incursionar pelo campo em algumas ocasiões ao longo desse período, mas me faltaram referências ou contatos que me proporcionassem a significação e a segurança que considerava indispensáveis para a realização da atividade. Recentemente, tais faltas foram sanadas através do contato com pessoas próximas que se tornaram sujeitos ativos no campo em questão, o que facilitou a consumação de minha 
primeira participação, ocorrida no penúltimo final de semana do mês de fevereiro deste ano. A singularidade e intensidade da experiência e o universo de novos conhecimentos, valores e práticas relacionadas a ela aguçaram ainda mais minha curiosidade e fortaleceram minha disposição para estudar o tema, sendo que quando surgiu a proposta de elaboração de um relato etnográfico, imaginei que seria uma boa oportunidade para desenvolver tal pesquisa, dadas as características do trabalho. Aqui, novamente, o contato com sujeitos do campo foi um diferencial, dada a importância da figura do informante para esse tipo de trabalho. Por se tratar, em alguns casos, de pessoas próximas, com quem tenho contato direto e frequente, além de uma relação de confiança, o acesso a informações, outros sujeitos e ao próprio campo seria privilegiado, o que facilitaria o desenvolvimento e incrementaria a qualidade da pesquisa.

O trabalho de observação participante se deu em dois espaços distintos que promovem rituais de ayahuasca e através do engajamento em um ritual realizado em cada um desses espaços. Devido às atividades, à dinâmica e à proposta relacionadas ao campo de pesquisa escolhido, creio que meu trabalho prático adquiriu um caráter peculiar, diferenciando-se daqueles desenvolvidos em outros ambientes. Nas palavras de Beatriz Labate, referindo-se à pesquisa de campo no contexto de rituais com ayahuasca:

“[...] não há mais observação participante enquanto uma combinação de 'observação' e de 'participação': há participação integral que afeta drasticamente a natureza da observação (que inclui a 'sensibilidade' e a 'razão')". (LABATE, 2004, p. 50-51)

Por conta dessa particularidade, meus relatos são focados justamente nos momentos iniciais ou finais dos rituais, quando minha percepção e minha consciência estavam menos influenciadas pelos efeitos da bebida, ou em elementos do campo pouco vinculados à temporalidade, como suas características arquitetônicas, por exemplo. Também optei por trabalhar dessa forma com vistas a um melhor aproveitamento pessoal da experiência ritualística, já que não estaria ocupado em obter material ou fazer observações durante todo o tempo.

O primeiro espaço é um sobrado aparentemente comum, localizado em São Bernardo do Campo, em um bairro afastado do centro da cidade e próximo aos limites da zona metropolitana. A fachada e as partes dianteira e central do imóvel constituem uma residência convencional, enquanto nos fundos há um grande salão retangular dividido em duas partes, no qual ocorrem as atividades dos rituais, além de um banheiro, um pequeno cômodo intermediário no interior da casa e um corredor externo, sendo que esses dois últimos estabelecem a ligação entre as partes. Durante os trabalhos, os participantes têm livre acesso 
aos quatro ambientes dos fundos do imóvel, mas é recomendado que permaneçam durante a maior parte do tempo no interior do salão, que é preparado de acordo com as necessidades e finalidades dos rituais.

O segundo espaço é uma chácara em Campo Limpo Paulista. O terreno é extenso e abriga, nesta ordem, a residência do caseiro e sua família, a casa do proprietário e sua família, e o local onde são realizados os trabalhos. Este último ambiente é constituído por um salão amplo e arejado - com muitas portas e janelas -, construído em formato circular e com aspecto rústico, uma cozinha, um cômodo que serve de vestiário e guarda-volumes, quatro banheiros - dois masculinos e dois femininos - e uma área externa. Os rituais ocorrem principalmente dentro do salão, mas há a possibilidade de transitar pelos outros ambientes, embora, novamente, a permanência nesses locais não seja recomendada.

Ambos os espaços são decorados com imagens e objetos religiosos e esotéricos de origens diversas - cristãs, indígenas, orientais, etc. -, com a diferença notável de que no primeiro havia presença maciça de entidades relacionadas a religiões e cultos de origem africana, enquanto no segundo estas estavam completamente ausentes. Além disso, durante os rituais, os ambientes ficam iluminados apenas com luz negra ou de baixa intensidade e luz de velas, sendo que em outros momentos, antes e depois dos rituais, a iluminação é feita com lâmpadas comuns ou luz natural - isto apenas no segundo espaço, após o nascer do Sol.

Os dois espaços visitados também compartilham alguns aspectos estruturais e procedimentais quanto aos rituais. Os trabalhos dos quais participei começaram entre $19 \mathrm{~h} 00 \mathrm{e}$ 21 h00 e se estenderam pela madrugada, terminando apenas nas primeiras horas da manhã. Primeiramente, há uma palestra do(s) dirigente(s), na qual são explicadas a estrutura, os procedimentos e as regras do ritual, e também são passadas algumas recomendações relacionadas ao melhor aproveitamento da experiência. Após essa etapa de orientações mais técnicas, as falas e práticas do(s) palestrante(s) adquirem um caráter mais litúrgico, com orações, agradecimentos e pedidos de proteção espiritual para os participantes, o ambiente e o ritual, e então é anunciado o início dos trabalhos. Ao longo da noite, são administradas três doses de ayahuasca, em intervalos de 1h30min, sendo que todos os presentes devem obrigatoriamente tomar ("consagrar") ao menos a primeira. Fora isso, além de algumas poucas restrições comportamentais, os participantes têm certa liberdade para vivenciar a experiência da forma como preferirem, mas é recomendado que priorizem a apreciação introspectiva, de forma a potencializar os diversos efeitos psíquicos da bebida, incluindo suas potencialidades terapêuticas. 
Não obstante a influência do xamã e do processo ritual, a experiência transcendental é individual, pois cada indivíduo possui uma trajetória única, isto é, a experiência enteógena se interpenetra ao universo simbólico de cada um, apesar de todos compartilharem de um complexo cultural comum. $\mathrm{Ou}$ seja, o aspecto subjetivo em cada corpo, em cada organismo, em cada sujeito é único e relevante [...]. (PAIVA, 2015, p. 94)

Apesar dessa ênfase na experiência individual, ao longo dos rituais foram propostas algumas atividades coletivas, entre elas o bailado, apresentações musicais e utilização de outras medicinas naturais, como o rapé e a sananga, sendo que no segundo espaço visitado essa tendência foi mais acentuada. Ao final dos trabalhos, há ainda um momento dedicado ao compartilhamento de impressões e experiências, acompanhado por uma palestra de encerramento, após a qual ocorre uma refeição coletiva - os participantes contribuem trazendo alimentos leves e bebidas.

Gostaria de destacar que algumas de minhas observações são restritas às ocasiões específicas de minhas visitas, não constituindo características permanentes daqueles espaços, visto que ambos realizam trabalhos com temáticas variadas, o que pode ocasionar alterações na organização e decoração dos ambientes e em alguns aspectos da ritualística.

\section{Sujeitos da pesquisa}

Os sujeitos com quem trabalhei mais diretamente, inclusive realizando entrevistas, foram: (1) minha informante, que participa do campo como frequentadora, organizadora e dirigente de trabalhos com ayahuasca; (2) uma frequentadora, que também participa como auxiliar em alguns trabalhos; (3) um proprietário e gestor de um espaço onde ocorrem trabalhos com ayahuasca, que também atua como organizador e dirigente. Considero que outros participantes e dirigentes, com quem interagi de maneira indireta, breve ou superficial, durante as incursões a campo, também foram relevantes, de alguma forma.

Minha informante é alguém com quem me relaciono direta, íntima e frequentemente há algum tempo, antecedendo inclusive seu envolvimento mais profundo com o campo em questão. O sentimento mútuo de confiança e familiaridade e a regularidade de nossas conversas e encontros facilitaram muito a troca de ideias e informações, o acesso a outros sujeitos e ao próprio campo. Seu envolvimento multifacetado (como frequentadora, organizadora e dirigente) com o campo permitiu que eu tivesse contato com diferentes perspectivas, embora partindo de uma mesma pessoa, e já adiantou algumas das questões que seriam relevantes nas etapas seguintes.

O segundo sujeito com quem trabalhei é uma pessoa próxima à informante, que eu também já conhecia, mas com quem não tenho tanta intimidade, sendo que nunca havíamos 
conversado sobre o assunto da pesquisa com muita profundidade. Novamente, o fato de já nos relacionarmos, embora de forma mais distante, além do vínculo com a informante, facilitaram sua participação no trabalho, que consistiu principalmente em conversas informais, concessão de uma entrevista e acompanhamento em uma das visitas a campo.

O contato com o terceiro sujeito foi um pouco mais trabalhoso, mas creio que apenas pelo fato de não nos conhecermos previamente. Minha informante, que frequenta, organiza e dirige rituais no espaço gerido pelo sujeito, atuou como mediadora, contribuindo para o estabelecimento de uma relação de confiança entre as partes. Após apresentar brevemente a ideia do trabalho e confirmar o interesse de participação, me passou o contato do sujeito, com quem troquei mensagens via WhatsApp durante aproximadamente três semanas, explicando mais minuciosamente as intenções e procedimentos planejados para a pesquisa, esclarecendo suas dúvidas e combinando os detalhes de sua colaboração, que foi constituída por uma entrevista, realizada após um dos trabalhos que organizou e dirigiu, e do qual participei. Embora tenha exigido um pouco mais de paciência, todo o processo ocorreu de forma tranquila, com o sujeito mostrando-se interessado e solícito durante a maior parte do tempo apesar de alguma desconfiança inicial, superada após algumas mensagens.

Obviamente, devido à proposta da pesquisa, algumas das questões abordadas nas conversas informais e entrevistas realizadas com meus colaboradores eram relacionadas com os potenciais aspectos terapêuticos do uso da ayahuasca, e posso dizer que os três participantes foram afirmativos quanto a essa possibilidade, mesmo quando a hipótese não foi mencionada explicitamente por mim. Vale destacar que minha informante (e primeiro sujeito da pesquisa) e o terceiro sujeito são terapeutas profissionais - psicóloga e psicanalista, respectivamente -, e ambos se referiram de maneira enfática à faceta psicoterápica dos rituais e seus desdobramentos, em diversos momentos de nossas conversas e encontros. Enquanto adeptos do uso ritualístico da ayahuasca, os três sujeitos relataram diversos benefícios psíquicos, emocionais e relacionais, que foram inclusive elencados como algumas das motivações para a continuidade e aprofundamento nas práticas xamânicas. Na posição de organizadores e dirigentes de rituais, minha informante e o terceiro sujeito expressaram interesses e preocupações aparentemente associados a um sentimento de missão, no sentido de ajudar os participantes dos trabalhos a usufruir mais plenamente dos efeitos terapêuticos da ayahuasca, relacionados por eles a uma melhoria na qualidade de vida.

\section{Descrição de uma experiência}


Ao final de cada trabalho, há um momento dedicado aos testemunhos dos participantes, a respeito de suas experiências naquela ocasião. Apenas uma pessoa deve falar por vez, compartilhando seu relato publicamente, enquanto as outras permanecem em silêncio, talvez esboçando discretas reações ao que está sendo dito, mas de forma a não interromper ou constranger aquele que estiver com a palavra. É um momento interessante e revelador, visto que, após horas de trabalho introspectivo potencializado pelos diversos efeitos da ayahuasca, os participantes geralmente têm muitos conteúdos psíquicos e emocionais a elaborar, e alguns se sentem impelidos a expressá-los ali. Feita esta pequena contextualização, gostaria de destacar a fala de um participante, ocorrida nesta etapa final da segunda incursão a campo, que se relaciona à hipótese inicial desta pesquisa. O palestrante revelou que era um psiquiatra cético quanto a questões religiosas e esotéricas, e discorreu sobre o processo que o levou até aquele ritual, relatando que fora convidado por um pedreiro que estava trabalhando em sua casa, e com quem desenvolveu uma relação de amizade. Inicialmente, disse que tratou o convite do amigo com certa desconfiança e desdém, por conta de suas inclinações céticas e sua postura cientificista na abordagem das questões da mente, mas terminou aceitando a proposta, incentivado por seu companheiro, que também estava presente na ocasião. A partir daí, compartilhou maravilhado algumas de suas impressões sobre os acontecimentos daquela noite, sobre as quais não entrarei em detalhes, revelando algumas mudanças ou questionamentos de crenças e perspectivas anteriores, e agradecendo vigorosamente a todos os participantes. Encerrou sua fala com agradecimentos especiais ao amigo que o convidou e a seu companheiro que o convenceu a comparecer, afirmando que aquela experiência havia sido equivalente a dezenas de sessões de terapia convencional.

\section{Uma proposta de interpretação}

O uso da ayahuasca já foi investigado de maneira variada e significativa por pesquisadores de diversas áreas, e, apesar de não existirem estudos potencialmente conclusivos a respeito de alguns de seus efeitos, principalmente em longo prazo, indicações positivas a respeito de benefícios psíquicos, emocionais e até mesmo físicos foram fornecidas por inúmeras abordagens científicas. Dito isto, considero que minha pesquisa se soma a tal conjunto de trabalhos, visto que minha hipótese referencial, relacionada ao caráter terapêutico dos rituais com ayahuasca e seus desdobramentos, foi satisfatoriamente corroborada por minhas experiências e observações em campo e pela relação com os sujeitos. 


\section{Referências Bibliográficas}

GEERTZ, C. A interpretação das culturas. Rio de Janeiro: LTC, 2008.

LABATE, B. A Reinvenção do uso da ayahuasca nos centros urbanos. São Paulo: Fapesp, 2004.

PAIVA, V. S. Ayahuasca, experiências e neoxamanismo: Um estudo etnográfico junto ao Grupo Xamânico Caminho do Arco-Î́ris - Pelotas/RS. Rio Grande do Sul: UFPel, 2015.

TADDEI, A. Sobre a escrita etnográfica. Revista Aurora, vol. 5. Marília: Unesp, 2012. 